\title{
Efficient wireless power transmission to remote the sensor in restenosis coronary artery
}

\author{
Mokhalad Alghrairi ${ }^{1,3}$, Nasri Sulaiman ${ }^{1}$, Wan Zuha Wan Hasan ${ }^{1}$, Haslina Jaafar ${ }^{1}$, Saad Mutashar ${ }^{2}$ \\ ${ }^{1}$ Department of Electrical and Electronic Engineering, Faculty of Engineering, Universiti Putra Malaysia, Selangor, Malaysia \\ ${ }^{2}$ Department of Electrical Engineering, University of Technology-Iraq \\ ${ }^{3}$ Department of Computer Techniques Engineering, Imam Al Kadhim College (IKC), Baghdad, Iraq
}

\begin{abstract}
Article Info
Article history:

Received Oct 13, 2021

Revised Dec 21, 2021

Accepted Dec 27, 2021

\section{Keywords:}

In stent restenosis

Magnetic resonance coupling

Power transfer efficiency

Stent

Wireless power transmission

ABSTRACT

In this study, the researchers have proposed an alternative technique for designing an asymmetric 4 coil-resonance coupling module based on the series-to-parallel topology at $27 \mathrm{MHz}$ industrial scientific medical (ISM) band to avoid the tissue damage, for the constant monitoring of the in-stent restenosis coronary artery. This design consisted of 2 components, i.e., the external part that included 3 planar coils that were placed outside the body and an internal helical coil (stent) that was implanted into the coronary artery in the human tissue. This technique considered the output power and the transfer efficiency of the overall system, coil geometry like the number of coils per turn, and coil size. The results indicated that this design showed an $82 \%$ efficiency in the air if the transmission distance was maintained as 20 $\mathrm{mm}$, which allowed the wireless power supply system to monitor the pressure within the coronary artery when the implanted load resistance was $400 \Omega$.
\end{abstract}

This is an open access article under the CC BY-SA license.

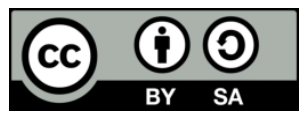

\section{Corresponding Author:}

Mokhalad Alghrairi

Department of Electrical and Electronic Engineering, Faculty of Engineering, Universiti Putra Malaysia

Selangor, Malaysia

Email: mokhalad.khalel@alkadhum-col.edu.iq

\section{INTRODUCTION}

In-stent restenosis related to the coronary artery is described as the re-narrowing of the artery due to many factors like the presence of a blood clot. In-stent restenosis can be effectively used as an early-warning sign or diagnostic tool for monitoring cardiac health [1]-[3]. For the past many years, wireless sensors have been used in different biomedical applications. Numerous researchers have studied telemetric medical diagnostic functioning using the radio frequency (RF) [4]-[6]. All these techniques need to be designed efficiently for satisfying the conditions of resonance and power transmitted to the receiver coil (i.e., stem) from a transmitter coil. A stent represents a receiver coil that is integrated with the capacitive pressure sensor for creating a pressure-sensitive circuit that displays a wireless sensing capability.

2 coils based on the wireless power transmission (WPT) system has many issues like a low-quality factor $(\mathrm{Q})$ and a low coupling coefficient $(\mathrm{K})$ owing to the size and source of the implanted coil. Thus, the maximal achievable power transfer efficiency (PTE) was very low in these systems [7]-[10]. The PTE of the WPT system was dependent on the structure and dimension of the coils, physical spacing between both the coils, environment and relative location of the different coils [11]. In [12] the researchers designed the 2 coils using the inductive coupling system, wherein the receiver coil was designed as a $38 \mathrm{~mm}$-long helical stent when the PTE was $\geq 0.03$. They tested these coils through the subdermal tissue. It was noted that the significant size difference between the transmitter and the receiver coils could significantly decrease the energy coupling, thereby affecting the PTE and the stable output of the WPT system [13]-[15]. Hence, the 
resonant-based power delivering system has garnered a lot of popularity in the past few years [16]-[18]. Some other researchers also designed 2 coils using the resonance coupling technique, where the receiver coil was designed as the helical stent that was $23 \mathrm{~mm}$ long when PTE $\geq 0.09$. This design showed a low efficiency even when it was tested in the air with a distance $<5 \mathrm{~mm}$ [19]. In another design, the researchers presented 3 coils in the form of transmitter, booster and receiver (stent) coils, by applying the resonance coupling technique, wherein the stent length was $20 \mathrm{~mm}$. This design satisfied the low PTE of 40.8-0.8; at a distance of 5-15 mm respectively [16]. Despite these design alterations, it was noted that the distance and the PTE factors could not be applied in a remote sensor in the coronary artery as the distance had to be $\geq 20 \mathrm{~mm}$ [20]. The researchers designed a new 4 resonator coil structure, with a series-to-series topology for improving the system efficiency. They designed the source and the load coils such that they achieved a higher loaded Q quality factor and a maximal cross-coupling coefficient, thereby significantly improving the system efficiency. However, this was possible only when the distance between the primary and secondary sides showed no effect on the primary side. Hence, a single boosting effect was noted that was similar to the 3-coil resonator system [21]. In another study, the researchers used an asymmetric 4-resonator coil series-to-series topology for acquiring a low research modeling system (RMS) current within the primary side [22]. However, they noted a low system efficiency when they used the series-to-series topology in the compensation circuits.

Based on the previous related works which was clarified in the above introduction, it was noted that the efficiency of the transmitted energy of the two coils (external and the implanted) is still the issue in the far distance. Especially, in a coronary artery sensor as well as the use of the series-to-series topology in the design of four-coils are also useless in transmitting energy with high efficiency. In this study, the researchers have designed a high-performance, medium and long-distance WPT system as long as high efficiency transmission by using series to parallel topology. In this system, they used an asymmetric 4-coil series to parallel compensations, wherein 3 planar coils were used on the transmitter side while 1 helical coil was used as the stent in the receiving side. This design helped in acquiring a high PTE value when the distance between the remote implanted sensors was high. They tested this system in air.

\section{METHODOLOGY}

The general WPT system is made of 2 parts, i.e., external and internal components. The external component is placed outside the body, but it touches the skin; while the internal component is placed within the coronary artery in the human tissue. Figure 1 presents a schematic representation of the proposed 4-coil WPT system used to transfer the power for coronary artery sensor.

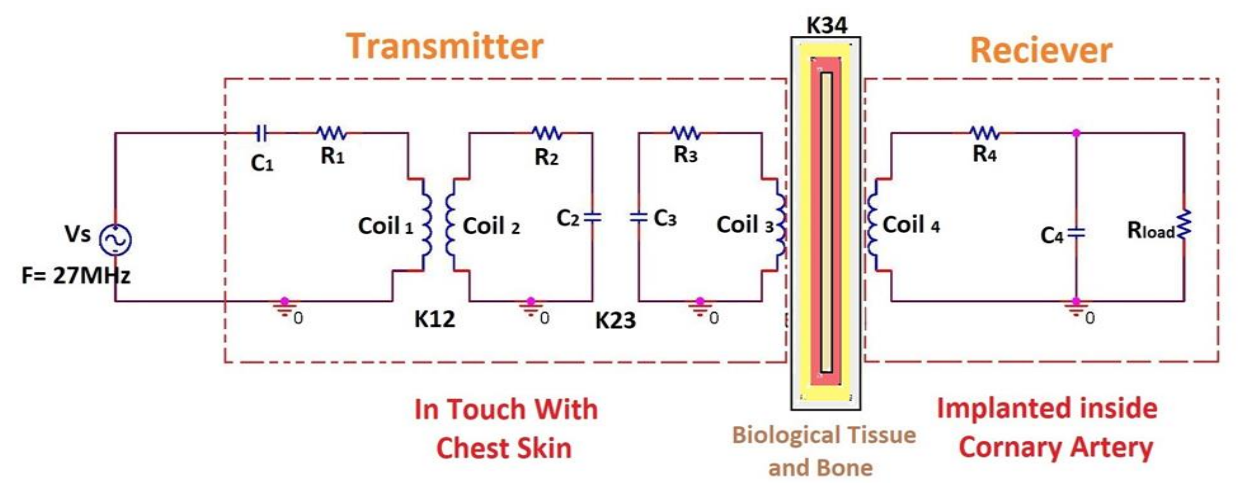

Figure 1. A Schematic of 4 coils wireless power transmission (WPT) system, series to parallel (S-P) topology

Here, Vs was the source voltage; L1, R1, and C1 were the inductance, resistance and the capacitance of source coil, respectively. Furthermore, L2, R2, and C2 were the equiv-alent inductance, resistance and capacitance values for the primary intermediate coil respectively; whereas; L3, R3, and C3 were the equivalent inductance, resistance and capacitance values of the 2nd intermediate coil, respectively. Additionally, L4, R4, C4, and Rload were the inductance, resistance, capacitance and load resistance values of the receiver side, respectively. The researchers noted that the PTE was improved due to the double boosting ef-fect, which, in turn, significantly increased the apparent coupling at the switching frequency. The high coupling coefficient generated the circulating current that did not help in the energy transfer for decreasing the load at the primary side, thereby lower-ing the RMS input current. 
In this design, the proposed coils were seen to be in resonance, wherein $\omega \mathrm{s}=\omega 1=\omega 2=\omega 3$. Also, the researchers selected the RF of $27 \mathrm{MHz}$ based on the industrial scientific medical (ISM) band [23], since it was not very invasive to the biological tissues and higher data rate. When this circuit theory was applied to Figure 1, the researchers determined the relationship be-tween the voltage applied at the source and current passing through every coil, which was expressed as follows:

$$
\begin{aligned}
& \left(R_{1}+J \omega M_{21}+J \omega M_{31}+J \omega M_{41}\right) I_{1}=V_{1} \\
& \left(R_{2}+J \omega M_{12}+J \omega M_{32}+J \omega M_{42}\right) I_{2}=0 \\
& \left(R_{3}+J \omega M_{13}+J \omega M_{23}+J \omega M_{43}\right) I_{3}=0 \\
& \left(R_{p}+J \omega M_{14}+J \omega M_{24}+J \omega M_{34}\right) I_{4}=0
\end{aligned}
$$

The far distance between coill and coil4 lead to be the coefficient coupling K13, K14 are very small and will be neglect the value.

$$
\left[\begin{array}{cccc}
R_{1} & A & 0 & 0 \\
A & R_{2} & B & 0 \\
0 & B & R_{3} & C \\
0 & 0 & C & R_{p}
\end{array}\right]\left[\begin{array}{c}
I_{1} \\
I_{2} \\
I_{3} \\
I_{4}
\end{array}\right]=\left[\begin{array}{c}
V_{1} \\
0 \\
0 \\
0
\end{array}\right]
$$

Where,

$$
\begin{aligned}
& A=J \omega M_{12}, B=J \omega M_{23}, C=J \omega M_{34}, R_{p}=\frac{R_{4} \times R_{\text {load }}}{R_{4}+R_{\text {load }}}, Q_{p}=\frac{Q_{L}+Q_{4}}{Q_{L} Q_{4}}, Q_{L}=\frac{\omega L_{4}}{R_{\text {load }}} \\
& I_{1}=\frac{V_{1}\left(R_{2} R_{3} R_{p}-R_{2} C^{2}-B^{2} R_{p}\right)}{R_{1} R_{2} R_{3} R_{p}-R_{1} R_{2} C^{2}-B^{2} R_{1} R_{p}-A^{2} R_{3} R_{p}+A^{2} C^{2}} \\
& I_{4}=\frac{-V_{1}\left(R_{2} R_{3} R_{p}-R_{2} C^{2}-B^{2} R_{p}\right)}{R_{1} R_{2} R_{3} R_{p}-R_{1} R_{2} C^{2}-B R_{1} R_{p}-A^{2} R_{3} R_{p}+A^{2} C^{2}} \\
& P_{\text {out }}=I_{4}^{2} \times R_{\text {load }} \\
& P_{\text {in }}=I_{1} V_{1}
\end{aligned}
$$

The efficiency between the transmitter and receiver for overall system is devel-oped and it will be (7).

$$
\eta=\frac{K_{12}^{2} K_{23}^{2} K_{34}^{2} Q_{1} Q_{2}^{2} Q_{3}^{2} Q_{p}}{\left(1+K_{34}^{2} Q_{3} Q_{p}+K_{23}^{2} Q_{2} Q_{3}\right)\left(1+K_{34}^{2} Q_{3} Q_{p}+K_{23}^{2} Q_{2} Q_{3}+K_{12}^{2} Q_{1} Q_{2}+K_{12}^{2} K_{34}^{2} Q_{1} Q_{2} Q_{3} Q_{p}\right)} \times \frac{R_{\text {load }}}{R_{\text {load }}+R_{4}}
$$

\section{COIL DESIGN}

In Step 1, the researchers specified the different design parameters of the 4-coil WPT system used for the biomedical implants. Table 1 presents the constraints of the proposed design with regards to the coupling distance, size, carrier frequency, fabrication technology, and load resistance for the transmitter coils. The transmitter planar coils included asymmetric 3-coil (dimension of $80 \times 80 \mathrm{~mm}$ ) for fulfilling the distance criteria that was given as dout $\leq \mathrm{D} \times 2 \sqrt{2}$ as shown in Figure 2 which is highlights the structure.

Table 1. The parameter values of the three coils for transmitter part

\begin{tabular}{lcr}
\hline \multicolumn{1}{c}{ Quantity } & Symbol & coil 1\&2\&3 \\
\hline Outer diameter & $\mathrm{d}_{\text {out }}$ & $80 \mathrm{~mm}$ \\
Inner diameter & $\mathrm{d}_{\text {in }}$ & $30 \mathrm{~mm}$ \\
Average diameter & $\mathrm{d}_{\text {avg }}$ & $55 \mathrm{~mm}$ \\
Number of turns for square coil & $\mathrm{N}$ & 25 \\
Inductor Width & $\mathrm{W}$ & $0.6 \mathrm{~mm}$ \\
Turn spacing & $\mathrm{S}$ & $0.4 \mathrm{~mm}$ \\
Fill factor & $\Phi$ & 0.45 \\
Thickness of conductor & $\mathrm{t}_{\mathrm{c}}$ & $0.3 \mathrm{~mm}$ \\
Quality factor coil1 & $\mathrm{Q}_{1}$ & 507.09 \\
Quality factor coil2 & $\mathrm{Q}_{2}$ & 598.36 \\
Quality factor coil3 & $\mathrm{Q}_{3}$ & 807.79 \\
\hline
\end{tabular}




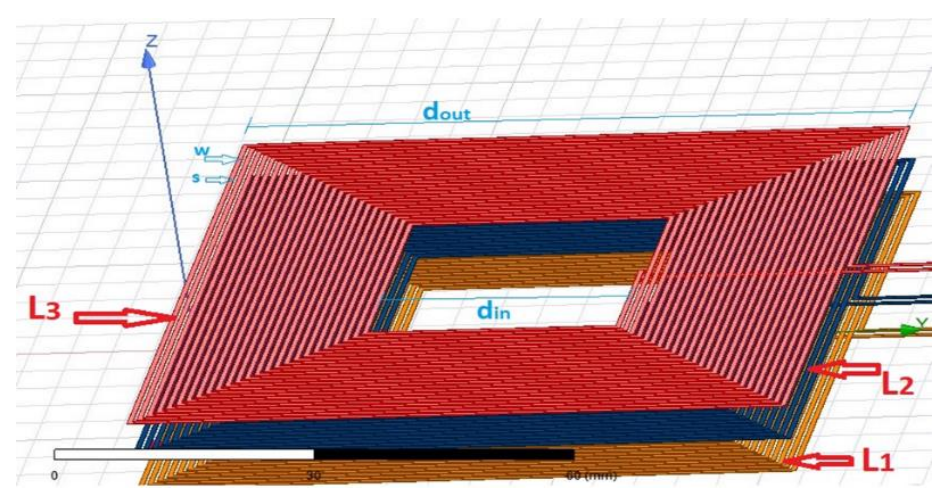

Figure 2. Structure of the proposed transmitter three planar coils

The inductance of planar coil calculates from (8) [24].

$$
L=\frac{1.27 \mu N_{\text {square }}^{2} d_{\text {avg }}}{2}\left[\ln \left(\frac{2.07}{\emptyset}+0.18 \emptyset+0.13 \emptyset^{2}\right)\right]
$$

Where N_square is the number of turns for square coil, $\mu$ is permeability, and $d_{\text {avg }}=\frac{d_{o u t}+d_{\text {in }}}{2}$, where $\mathrm{d} \_$in and d_out are the inner and outer side lengths of the coil, respectively.

$\emptyset=\frac{d_{o u t}-d_{\text {in }}}{d_{\text {out }}+d_{\text {in }}}$ is a parameter known as fill factor, which changes from zero, when all of the turns are concentrated on the perimeter in filament coils, and to one when the turns spiral all the way to the center of coil.

It was noted that the quality factor of the transmission and receiver coils, i.e., Q1, Q2, Q3 and Q4; was based on the coil inductance, resonance frequency and parasitic re-sistance that were calculated using (9).

$$
Q_{1}=\frac{\omega L_{1}}{R_{1}}, Q_{2}=\frac{\omega L_{2}}{R_{2}}, Q_{3}=\frac{\omega L_{3}}{R_{3}}, Q_{4}=\frac{\omega L_{4}}{R_{4}}
$$

The capacitance for circuit can calculated from (10), (12) [4], and (11) respectively [22].

$$
\begin{aligned}
& C_{1}=C_{\text {amplifier }}\left[\frac{5.447}{Q_{\text {amplifier }}}\right]\left[1+\frac{1.42}{Q_{\text {amplifier }}-2.08}\right] \\
& C_{2}=\frac{1.3924}{L_{2} \omega_{s}^{2}}, C_{3}=\frac{1.8225}{L_{3} \omega_{s}^{2}} \\
& C_{4}=\frac{R_{\text {load }}+\sqrt{R_{\text {load }}^{2}-4 \omega^{2} L_{4}^{2}}}{2 \omega^{2} R_{\text {load }} L_{4}}
\end{aligned}
$$

Where Rload presents the implanted resistance and should be Rload $\geq 2 \omega \mathrm{s}$ L4 [25]. The parasitic resistance $\mathrm{R} 4$ is calculated as given in (13).

$$
R_{4}=\frac{R_{\text {load }}}{1+\omega_{0}^{2} R_{\text {load }}^{2} C_{4}^{2}}
$$

The receiver coil (i.e., stent) was regarded as a helical coil that was expanded from the zigzag helical stent to a helical shape [26]. Increases in stent lengths not exceeding $40 \mathrm{~mm}$ leads to increased power transfer efficiencies and mutual inductance, based on the commercial stent standard ISO 25539. However, increases in length leads to in-creases in the tissue surrounding the stent and inhibits problematic restenosis, so the stent length is select to be $30 \mathrm{~mm}$. Strut cross-sectional area is also critical in-stent restenosis. A square strut cross-sectional area with sharp edges is not recommended, for it will interfere with fluid blood flow and may also slice blood cells. Therefore, Round strut cross-sectional areas without corners and sharp edges are safer in reduc-ing restenosis. Figure 3 presents the structure of this helical stent design proposed in the study. Table 2 lists the design constraints in terms of the size, coupling distance, fabrication technology, carrier frequency, and load resistance for receiver coil (stent). 


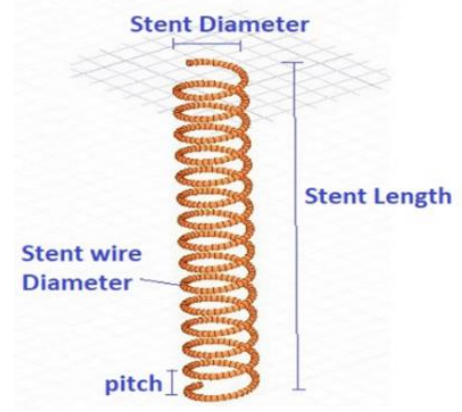

Figure 3. Shows the structure of receiver helical coil (Stent)

Table 2. The parameter values of the stent for receiver part

\begin{tabular}{lcr}
\hline \multicolumn{1}{c}{ Quantity } & Symbol & Coil 4 \\
\hline Stent length & $1_{\text {stent }}$ & $30 \mathrm{~mm}$ \\
Stent Diameter & $\mathrm{d}_{\text {stent }}$ & $5 \mathrm{~mm}$ \\
pitch & $\mathrm{p}$ & $2 \mathrm{~mm}$ \\
Wire Diameter of stent & $\mathrm{d}_{\text {stent wire }}$ & $0.3 \mathrm{~mm}$ \\
Quality factor & $\mathrm{Q}_{4}$ & 6.72 \\
Number of turns for stent & $\mathrm{N}_{\text {stent }}$ & 15 \\
\hline
\end{tabular}

In a helical coil, self-inductance is calculated from (14) [27].

$$
L_{\text {helical coil }}=\frac{\mu \pi r^{2} N_{\text {stent }}^{2} T}{l_{\text {stent }}}
$$

Where $\mu$ is the permeability of free space, $r=d s t e n t / 2$, and $\mathrm{T}$ is Nagaoka's coefficient, approximated as,

$$
\begin{aligned}
& T=Y_{Z}\left(\ln \left(1+\frac{1}{Y_{Z}}\right) U\right) \\
& U=\frac{1}{\left(X_{0}+X_{1}\left(\frac{d_{\text {stent wire }}}{d_{\text {stent }}}\right)\right)+X_{2}\left(\frac{d_{\text {stent wire }}}{d_{\text {stent }}}\right)^{2}+\frac{a_{1}}{\left(a_{2}+\frac{d_{\text {stent }}}{d_{\text {stent wire }}}\right)^{v}}}
\end{aligned}
$$

Where $\quad Y_{z}=\frac{d_{\text {stent wire }}}{\pi r} \quad, \quad X_{0}=2.30038, X_{1}=3.437, X_{2}=1.76356, a_{1}=-0.47, a_{2}=0.755, v=$ $1.44, l_{c}=\pi d N$

This mutual inductance can also be considered as a unitless coupling coefficient between two coils and can get (17).

$$
K_{m n}=\frac{M}{\sqrt{L_{m} L_{n}}}
$$

\section{RESULTS AND DISCUSSION}

For ensuring that the results simulated using the proposed design were as close to reality as possible, the researchers used cork as the substrate between the 3 transmitter coils, with a permittivity, $\varepsilon 0=1$. This value was equivalent to the air permittivity value and did not affect the coupling between the 3 transmitter coils, thus achieving a high PTE. It is important to develop effective implanted devices as they directly affect the safety and lives of the people. The resonance coupling technique was seen to be the most appropriate technique that could be used for powering the battery-less devices. Here, the researchers used the serial-toparallel resonance coupling topology, wherein the 3 primary coils (reader) were tuned in the series resonance for presenting a lower impedance load for operating the transmitter coils. It was noted that the coil geometry like coil size and no of coils. played a vital role in this design. Table 3 presents the parameters used for every coil of the design like the implanted helical coil (stent) and the 3 rectangular spiral coils (i.e., transmitter). For improving the link efficiency, the researchers tuned the receiver and transmitter resistor-inductorcapacitor (RLC) circuits for the inductive link to the same RF value, i.e., $27 \mathrm{MHz}$. Figure 4 indicated that the RF values between Coil 1 and 2; Coil 2 and 3; Coil 3 and the receiver Coil 4, were tuned to $27 \mathrm{MHz}$. 
Table 3. Circuit parameters of the system design

\begin{tabular}{lcc}
\hline \multicolumn{1}{c}{ Description } & $\mathrm{Symbol}_{1}$ & Value \\
\hline First, second, third Coils inductance & $\mathrm{L}_{1}, \mathrm{~L}_{2}, \mathrm{~L}_{3}$ & $44.80 \mu \mathrm{H}$ \\
First capacitance & $\mathrm{C}_{1}$ & $0.80 \mathrm{PF}$ \\
First coil resistance & $\mathrm{R}_{1}$ & $14.98 \Omega$ \\
Second capacitance & $\mathrm{C}_{2}$ & $0.557 \mathrm{PF}$ \\
Second coil resistance & $\mathrm{R}_{2}$ & $14.98 \Omega$ \\
third capacitance & $\mathrm{C}_{3}$ & $0.557 \mathrm{PF}$ \\
third coil resistance & $\mathrm{R}_{3}$ & $14.98 \Omega$ \\
fourth Coil inductance & $\mathrm{L}_{4}$ & $0.355 \mu \mathrm{H}$ \\
fourth capacitance & $\mathrm{C}_{4}$ & $97.41 \mathrm{PF}$ \\
fourth coil resistance & $\mathrm{R}_{4}$ & $8.95 \Omega$ \\
Load resistance & $\mathrm{R}_{\text {load }}$ & $400 \Omega$ \\
Mutual inductance between coil3 and coil 4 & $\mathrm{M}_{34}$ & $0.212 \mu \mathrm{H}$ \\
Coupling coefficient between coil1 and coil 2 & $\mathrm{K}_{12}$ & 0.9 \\
Coupling coefficient between coil2 and coil 3 & $\mathrm{K}_{23}$ & 0.89 \\
Coupling coefficient between coil3 and coil 4 & $\mathrm{K}_{34}$ & 0.05 \\
Distance between coil 1 and coil 2 & $\mathrm{D}_{12}$ & $5 \mathrm{~mm}$ \\
Distance between coil 2 and coil 3 & $\mathrm{D}_{23}$ & $5 \mathrm{~mm}$ \\
Distance between coil 3 and coil 4 & $\mathrm{D}_{34}$ & $20 \mathrm{~mm}$ \\
Resonance frequency & $\mathrm{f}_{0}$ & $27 \mathrm{MHz}$ \\
Efficiency & $\eta$ & $82 \%$ \\
\hline
\end{tabular}

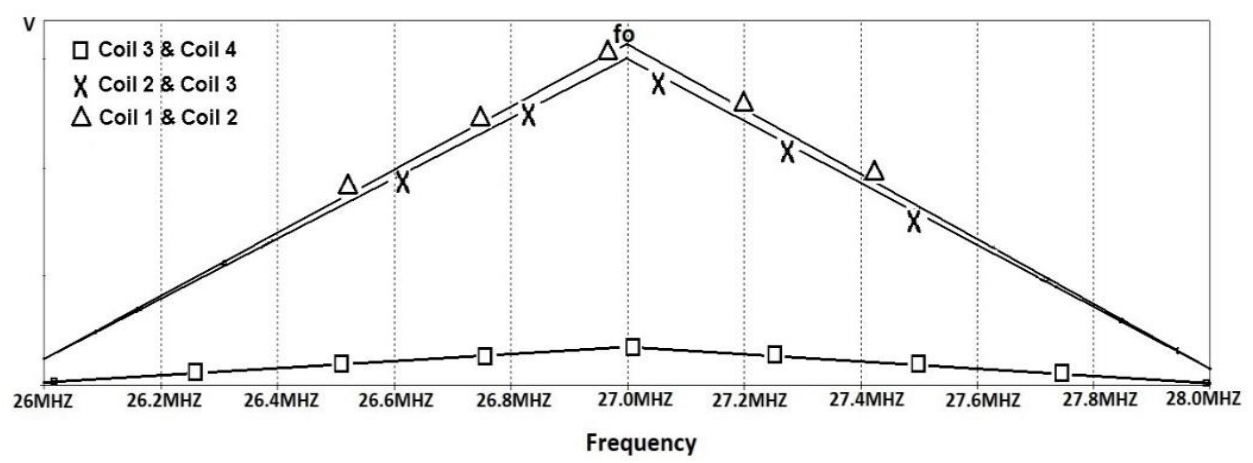

Figure 4. Shows the resonance frequency at $27 \mathrm{MHz}$ between coil 1 and coil2, coil2 and coil3, coil3 and coil4

The general system efficiency was determined using (7). Figure 5(a) describes the efficiency between the Planar Coil 3 and Helical Coil 4. It was seen that the variance coupling coefficient was high due to the distance variations. The system was $82 \%$ efficient at $\mathrm{K} 34=0.05$ in the air. The researchers established the load resistance as Rload $\geq 2 \omega \mathrm{s} L 4$; hence, they presumed that the Rload ranged from 200-1000 $\Omega$, based on the resistance of the implanted electronic remote as shown in Figure 5(b) In this study, the reference Rload was set at $400 \Omega$.

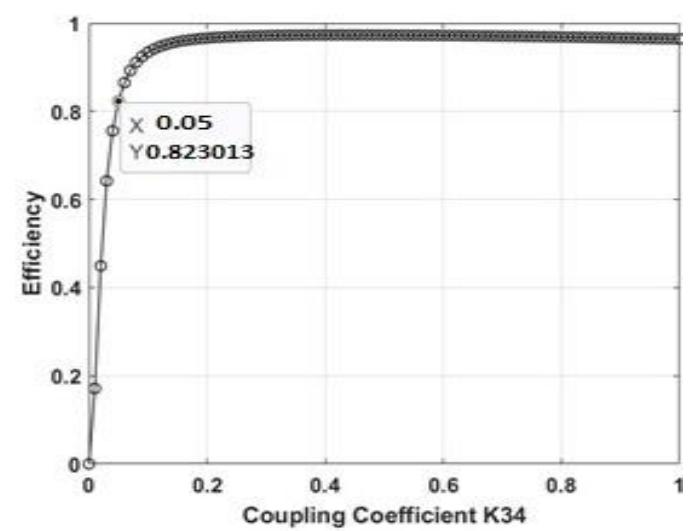

(a)

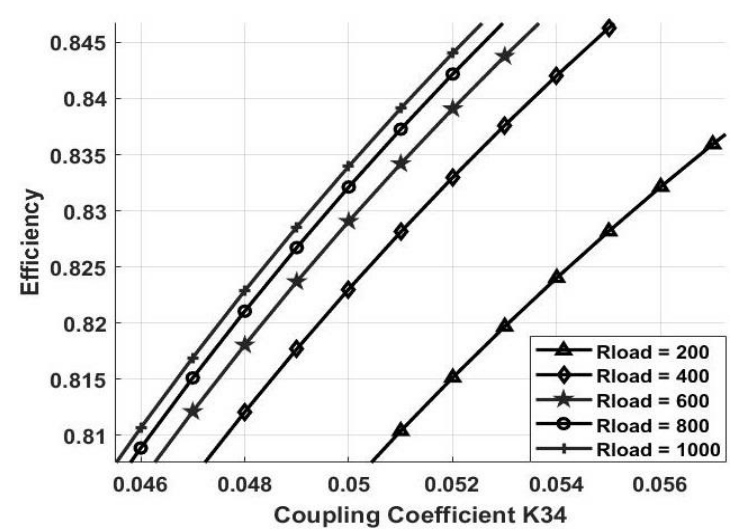

(b)

Figure 5. Efficiency between planar coil 3 and helical coil 4 (stent), where test in air (S-P Topology): (a) with R load at $400 \Omega$ and (b) with variable load resistance (200-1000) $\Omega$ 
While determining the resonance coupling, the researchers noted 2 important relationships, i.e., that between the distance and coupling coefficient and that between the distance and mutual inductance. Figure 6 describes the relationship between the coupling coefficient and distance for K14, K24, and K34. The nearest coil showed a better coupling coefficient than other coils, i.e., 0.05 at a distance of $20 \mathrm{~mm}$.

For investigating the magnetic properties of the helix and spiral coils, the re-searchers developed a few finite-element models for the spiral/helical coupling coils, using the COMSOL Multiphysics software, based on the parameters presented in Tables 1 and 2; and using other parameters like length of helix coil (stent). Figure 7 present the magnetic fluxes that was generated by the coils in the air, it also estimated the fluxes that were caused by the transmitting coils that passed through the receiving coil, which induced a current in the receiving coils. The currents, in turn, generated new magnetic fluxes that pass through the transmitting coils. A flux leakage was noted that did not pass via the coils. For validating the proposed design, the researchers compared the proposed design with other studies, as described in Table 4 . The results indicated that their proposed design showed a better PTE and a high transmission distance between the coils.

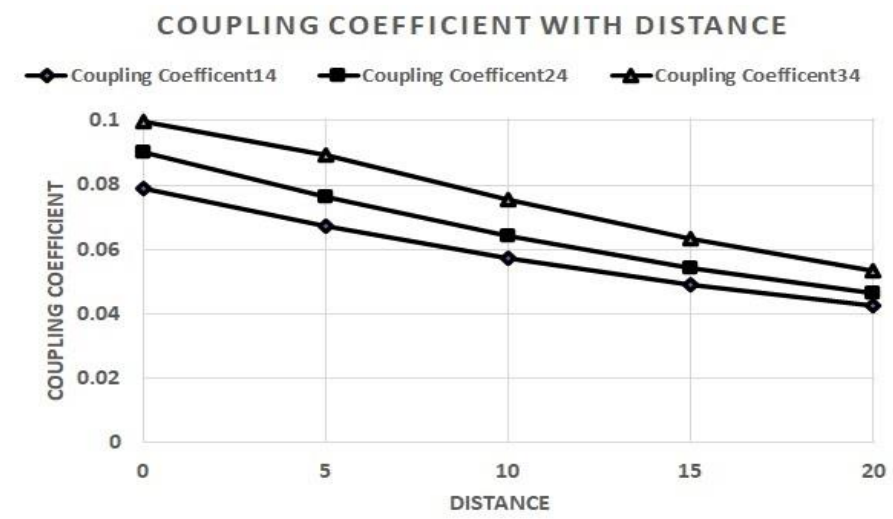

Figure 6 . The relation between the coupling coefficient $(\mathrm{K})$ and distance for coil12 and coil24 and coil34

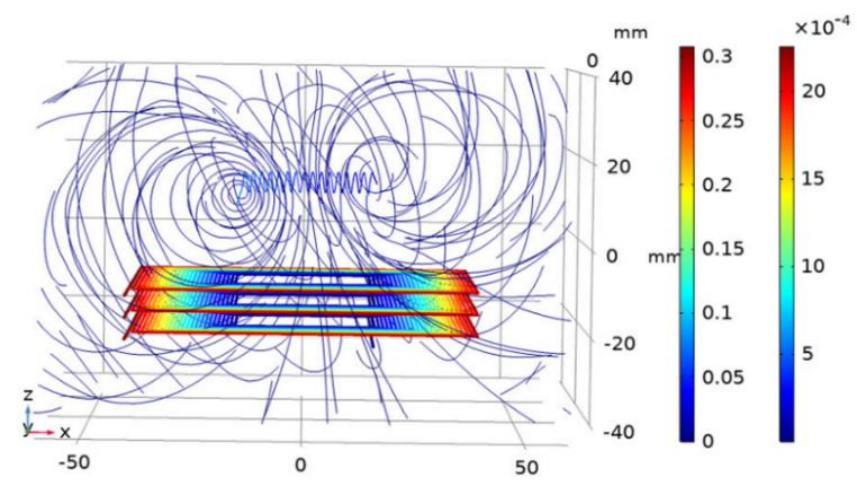

Figure 7. Shows the magnetic flux around transmitter and receiver coils

Table 4. Table for validation of result gathered compared with other researchers

\begin{tabular}{|c|c|c|c|c|c|c|}
\hline Refrences & $\begin{array}{l}\text { Stent length } \\
(\mathrm{mm})\end{array}$ & $\begin{array}{c}\text { Powering } \\
\text { method }\end{array}$ & $\begin{array}{c}\text { Input power } \\
(\mathrm{dBm})\end{array}$ & $\begin{array}{c}\text { Transmission } \\
\text { medium }\end{array}$ & $\begin{array}{l}\text { Transmission distance } \\
(\mathrm{mm})\end{array}$ & $\begin{array}{c}\text { Power transfer } \\
\text { efficiency } \%\end{array}$ \\
\hline$[12]$ & 38 & inductive & 70 & Subdermal tissue & $\begin{array}{c}0 \\
\text { Inside antenna }\end{array}$ & $\geq 0.03$ \\
\hline [10] & 15 & inductive & 70 & $\begin{array}{c}\text { Bioartificial vessel, } \\
\text { water }\end{array}$ & $\begin{array}{c}0 \\
\text { Inside antenna }\end{array}$ & 0.52 \\
\hline [19] & 23 & resonant & 25 & Air & 5 & 0.09 \\
\hline [16] & 20 & resonant & 33 & Meat tissue & $5-15$ & $40.8-6.8$ \\
\hline This paper & 30 & resonant & 23.979 & Air & 20 & $82 \%$ \\
\hline
\end{tabular}

\section{CONCLUSION}

The inductive coupling link is generally used for powering the batteries in medical and bioimplanted devices. The system efficiency of these devices is significantly affected by the input impedance. In 
this study, a novel wireless transmission system in series to parallel topology is proposed. A highperformance, long distance WPT that included 3 asymmetric coils with stent arranged in a series-to-parallel topology, where 3 planar coils were used at the transmitter side and 1 helical coil was used as the stent in the receiving side. The efficiency of the proposed design satisfied the condition of efficient transfer power as the external component was placed at a higher distance from the internally implanted sensors. The proposed design tested in air as well as a novel mathematical model for the general wireless transmission system is performed. Their results showed that their proposed design performed better than those presented in the earlier studies. This design achieved an $82 \%$ efficiency in air; when the transmission distance was $20 \mathrm{~mm}$ with coupling coefficient between coil 3 and coil 4 at 0.05 , which enabled the wireless power supply to supervise the blood pressure in the coronary artery.

\section{REFERENCES}

[1] S. R. Khan, S. K. Pavuluri, G. Cummins, and M. P. Desmulliez, "Wireless power transfer techniques for implantable medical devices: A review," Sensors, vol. 20, p. 3487, 2020, doi: 10.3390/s20123487.

[2] M. Alghrairi, N. Sulaiman, and S. Mutashar, "Health Care Monitoring and Treatment for Coronary Artery Diseases: Challenges and Issues," Sensors, vol. 20, p. 4303, 2020, doi: 10.3390/s20154303.

[3] M. K. Alghrairi, N. B. Sulaiman, R. B. M. Sidek, and S. Mutashar, "Optimization of spiral circular coils for bio-implantable micro-system stimulator at $6.78 \mathrm{MHz}$ ISM band," ARPN Journal of Engineering and Applied Sciences, vol. 11, pp. 7046-7054, 2016.

[4] N. S. M. Khaleel ALghrairi and R. S. S. Mutashar, "Simple and Efficient Transcutaneous Inductive Micro-System Device Based on ASK Modulation at 6.78 MHz ISM Band," Tehnički vjesnik, vol. 27, pp. 1478-1485, 2020, doi: 10.17559/TV20150602203115.

[5] N. H. Sebastián, N. V.Villaseñor, F.-J. Renero-Carrillo, D. D. Alonso, and W. C. Arriaga, "Design of a fully integrated inductive coupling system: a discrete approach towards sensing ventricular pressure," Sensors, vol. 20, p. 1525, 2020, doi: $10.3390 / \mathrm{s} 20051525$.

[6] M. Haerinia, "A State of Art Review on Wireless Power Transmission Approaches for Implantable Medical Devices," arXiv preprint arXiv:2003.01240, 2020.

[7] P. Yeon, M.-G. Kim, O. Brand, and M. Ghoovanloo, "Optimal design of passive resonating wireless sensors for wearable and implantable devices," IEEE Sensors Journal, vol. 19, pp. 7460-7470, 2019, doi: 10.1109/JSEN.2019.2915299.

[8] S. Mutashar, M. A. Hannan, S. A. Samad, and A. Hussain, "Analysis and optimization of spiral circular inductive coupling link for bio-implanted applications on air and within human tissue," Sensors, vol. 14, pp. 11522-11541, 2014, doi: $10.3390 / \mathrm{s} 140711522$.

[9] U.-M. Jow and M. Ghovanloo, "Modeling and optimization of printed spiral coils in air, saline, and muscle tissue environments," IEEE transactions on biomedical circuits and systems, vol. 3, pp. 339-347, 2009, doi: 10.1109/TBCAS.2009.2025366.

[10] M. G. Floren, R. W. Günther, and T. Schmitz-Rode, "Noninvasive inductive stent heating: alternative approach to prevent instent restenosis?," Investigative radiology, vol. 39, pp. 264-270, 2004, doi: 10.1097/01.rli.0000117881.42422.72.

[11] S. R. Khan and G. Choi, "Analysis and optimization of four-coil planar magnetically coupled printed spiral resonators," Sensors, vol. 16, p. 1219, 2016, doi:10.3390/s16081219.

[12] A. B. Levitt, K. Robinson, N. A. Chronos, and W. Daum, "External heating of stents by radio waves: pilot studies in rabbit aorta," Cardiovascular radiation medicine, vol. 4, pp. 133-138, 2003, doi: 10.1016/S1522-1865(03)00166-5.

[13] Y. Zeng, D. Qiu, X. Meng, B. Zhang, and S. C. Tang, "Optimized design of coils for wireless power transfer in implanted medical devices," IEEE Journal of Electromagnetics, RF and Microwaves in Medicine and Biology, vol. 2, pp. 277-285, 2018, doi: 10.1109/JERM.2018.2863955.

[14] W. Xin, G. Yan, and W. Wang, "A stable wireless energy transmission system for gastrointestinal microsystems," Journal of medical engineering \& technology, vol. 34, pp. 64-70, 2010, doi: 10.3109/03091900903402055.

[15] Q. Chen, S. C. Wong, K. T. Chi, and X. Ruan, "Analysis, design, and control of a transcutaneous power regulator for artificial hearts," IEEE Transactions on Biomedical Circuits and Systems, vol. 3, pp. 23-31, 2009, doi: 10.1109/TBCAS.2008.2006492.

[16] Y. Yi, J. Chen, and K. Takahata, "Wirelessly Powered Resonant-Heating Stent System: Design, Prototyping and Optimization," IEEE Transactions on Antennas and Propagation, 2019, doi: 10.1109/TAP.2019.2944553.

[17] L. L. Pon, C. Y. Leow, S. K. A. Rahim, A. A. Eteng, and M. R. Kamarudin, "Printed spiral resonator for displacement-tolerant near-field wireless energy transfer," IEEE Access, vol. 7, pp. 172055-172064, 2019, doi: 10.1109/ACCESS.2019.2893805.

[18] C. Li, B. Wang, R. Huang, and Y. Yi, "A Resonant Coupling Power Transfer System Using Two Driving Coils," Energies, vol. 12, p. 2914, 2019, doi: 10.3390/en12152914.

[19] Y. Luo, M. Dahmardeh, X. Chen, and K. Takahata, "A resonant-heating stent for wireless endohyperthermia treatment of restenosis," Sensors and Actuators A: Physical, vol. 236, pp. 323-333, 2015, doi: 10.1016/j.sna.2015.10.046.

[20] S. Huang, Z. Li, Y. Li, X. Yuan, and S. Cheng, "A comparative study between novel and conventional four-resonator coil structures in wireless power transfer," IEEE Transactions on Magnetics, vol. 50, pp. 1-4, 2014, doi: 10.1109/TMAG.2014.2331962.

[21] S. Moon, B.-C. Kim, S.-Y. Cho, C.-H. Ahn, and G.-W. Moon, "Analysis and design of a wireless power transfer system with an intermediate coil for high efficiency," IEEE Transactions on Industrial Electronics, vol. 61, pp. 5861-5870, 2014, doi: 10.1109/TIE.2014.2301762

[22] S. Moon and G.-W. Moon, "Wireless power transfer system with an asymmetric four-coil resonator for electric vehicle battery chargers," IEEE Transactions on Power Electronics, vol. 31, pp. 6844-6854, 2015, doi: 10.1109/TPEL.2015.2506779.

[23] M. A. Hannan, S. Mutashar, S. A. Samad, and A. Hussain, "Energy harvesting for the implantable biomedical devices: issues and challenges," Biomedical engineering online, vol. 13, p. 79, 2014, doi: 10.1186/1475-925X-13-79.

[24] S. S. Mohan, M. D. M. Hershenson, S. P. Boyd, and T. H. Lee, "Simple accurate expressions for planar spiral inductances," IEEE Journal of solid-state circuits, vol. 34, pp. 1419-1424, 1999, doi:10.1109/4.792620.

[25] G. B. Hmida, H. Ghariani, and M. Samet, "Design of wireless power and data transmission circuits for implantable biomicrosystem," Biotechnology, vol. 6, pp. 153-164, 2007, doi: 10.3923/biotech.2007.153.164. 
[26] A. R. Mohammadi, M. S. Mohamed Ali, D. Lappin, C. Schlosser, and K. Takahata, "Inductive antenna stent: design, fabrication and characterization," Journal of Micromechanics and Microengineering, vol. 23, p. 025015, 2013, doi: 10.1088/0960$1317 / 23 / 2 / 025015$.

[27] D. W. Knight, "An introduction to the art of solenoid inductance calculation with emphasis on radio-frequency applications," ver. 0.20, Feb, vol. 4, 2016, Available at:http://g3ynh.info/zdocs/magnetics/Solenoids.pdf.

\section{BIOGRAPHIES OF AUTHORS}

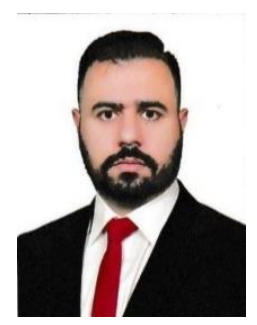

Mokhalad Alghrairi (iD $8 \mathrm{SC}$. is a Ph.D. student at the University Putra Malaysia (UPM). He Received a B.Sc degree in 2006 from Al-Mustansiriya University, Iraq, and M.Sc. degree in 2016 from the University Putra Malaysia (UPM). The field of interest, Microelectronics, Designing implantable micro-system stimulators, bio-medical implantable devices, healthcare monitoring and inductive coupling links for biomedical applications. He can be contacted at email: mokhalad.khalel@alkadhum-col.edu.iq.

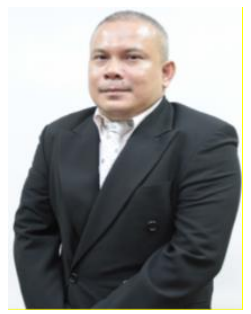

Nasri Sulaiman (iD) SC $\mathrm{SC}$ is an associate professor at the Department of Electrical and Electronic Engineering, Faculty of Engineering, Universiti Putra Malaysia. He received a bachelor degree in electronics and computer engineering from Universiti Putra Malaysia (UPM), Malaysia in 1994 and a master degree in microelectronics system design from University of Southampton, United Kingdom in 1999. He also obtained a Ph.D. degree in adaptive hardware from University of Edinburgh, United Kingdom in 2007. His areas of interest include evolutionary algorithms, digital signal processing, digital communications and low power VLSI designs. He is currently working on a variety of research projects such as "High Performance Hardware Implementation of a Multi-Objective Genetic Algorithm" which is funded through the Research University Grant Scheme (RUGS) of Universiti Putra Malaysia (UPM), as well as, "Crest Factor Reduction and Digital Pre-distortion Implementation in Orthogonal Frequency Division Multiplexing (OFDM) Systems“, funded by the Ministry of Science, Technology and Innovation (MOSTI). He can be contacted at email: nasri_sulaiman@upm.edu.my.

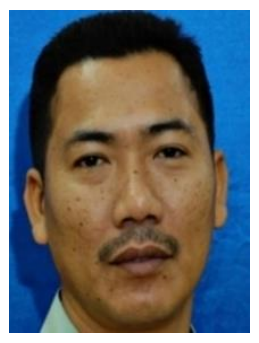

Wan Z. W. Hasan (D) 8D SC P is an Associate Professor at the Electrical and Electronics Engineering, Faculty of Engineering, Universiti Putra Malaysia (UPM). He received the B.Sc. degree in Electronic and Computer from the Universiti Putra Malaysia (UPM) in 1997, and the M.Sc. in Microelectronics from the Universiti Putra Malaysia (UPM) in 2001, and the Ph.D. in Memory Testing from the University Kebangsaan Malaysia (UKM) in 2005. He is a member IEEE member (BEM), IEEE Circuit and System Society (IEICE) and IEEE Electron and Devices (PPAUPM). His areas of specialization are Microelectronics, Sensor Technology, Robotic and Automation, especially in Pressure Sensor for Medical and Robotic and Automation Application, Mobile Robot, automated Machine and Memory Testing includes Built-in Self-test and Self-diagnose. He can be contacted at email: wan@upm.edu.my.

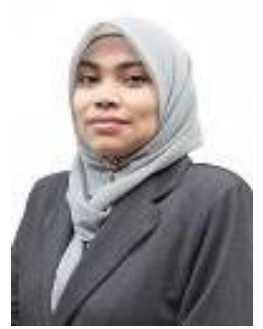

Dr. Haslina Jaafar (iD S SC P is currently a senior lecturer at the Department of Electrical and Electronics Engineering, Faculty of Engineering, Universiti Putra Malaysia. She obtained her B.Eng in Electrical, Electronics and Systems Engineering from Universiti Kebangsaan Malaysia in 1999. In 2001, she received her MSc in Microelectronics Engineering at the same institution. In 2014, she successfully achieved her PhD in Microelectronics Engineering from Universiti Sains Malaysia. Her research areas include Micro-Electro-Mechanical Systems (MEMS) and Microsystems, MEMS Sensor and Actuators and CMOS-MEMS integration. She can be contacted at email: jhaslina@upm.edu.my.

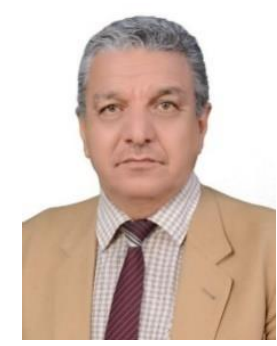

Saad Mutashar (D) Bd SC P Was born in Baghdad, Iraq 1961. Received B.Sc and M.Sc degrees in 1984 and 1986 respectively from University of Belgrade, Serbia. In 2014, he received his $\mathrm{PhD}$ degree from National University of Malaysia (UKM). Since 2005 he is an assist professor at the Department of Electrical Engineering, University of Technology, Iraq. The field of interest, Microelectronics, Designing implantable micro-system stimulator, biomedical implantable devices and inductive coupling links for bio-medical applications. More than 40 published papers at international scientific journals. Editor board and reviewer in several journals. $\mathrm{He}$ is an IEEE member. $\mathrm{He}$ can be contacted at email: Saad.m.abbas@uotechnology.edu.iq. 